NASA Technical Memorandum 106457

AIAA-94-0804

\title{
Close-up Analysis of Inflight Ice Accretion
}

Andrew L. Reehorst and Thomas P. Ratvasky

Lewis Research Center

Cleveland, Ohio

and

James Sims

Cortez III Service Corporation

Brook Park, Ohio

Prepared for the

32nd Aerospace Sciences Meeting and Exhibit

sponsored by the American Institute of Aeronautics and Astronautics

Reno, Nevada, January 10-13, 1994 


\title{
CLOSE-UP ANALYSIS OF INFLIGHT ICE ACCRETION
}

\author{
Andrew L. Reehorst, Thomas P. Ratvasky, \\ National Aeronautics and Space Administration \\ Lewis Research Center \\ Cleveland, Ohio 44135 \\ and \\ James Sims \\ Cortez III Service Corporation \\ Brook Park, Ohio 44142
}

\begin{abstract}
$\underline{\text { Abstract }}$
The objective of this effort was to validate in flight, data that has been gathered in the NASA Lewis Research Center's Icing Research Tunnel (IRT) over the past several years. All data was acquired in flight on the NASA Lewis Research Center's Twin Otter Icing Research Aircraft. A faired 3.5 in. diameter metal-clad cylinder exposed to the natural icing environment was observed by a close-up video camera. The grazing angle video footage was recorded to S-VHS video tape and after the icing encounter, the resultant ice shape was documented by $35 \mathrm{~mm}$ photography and pencil tracings. The feather growth area was of primary interest; however, all regions of the ice accretion, from the stagnation line to the aft edge of runback were observed and recorded. After analysis of the recorded data several interesting points became evident: (1) The measured flight feather growth rate is consistent with IRT values, (2) The feather growth rate appears to be influenced by droplet size, (3) The feathers were straighter in the lower, spottier LWC of flight in comparison to those observed in the IRT, (4) Feather shedding and ice sublimation may be significant to the final ice shape, (5) The snow encountered on these flights appeared to have little influence on ice growth.
\end{abstract}

\section{$\underline{\text { Introduction }}$}

Accurate prediction of ice accretions has long been a goal of the aerospace community. A great deal of effort has been expended in the last decade to develop computer programs which predict the resultant ice shape on airfoils for given environmental conditions (Refs. 1 to 7). The analytical models used by these computer programs were based upon the physical understanding of the ice accretion process at the time of their inception. However, inaccuracies have been identified in all of the ice accretion prediction programs. These inaccuracies have been linked to both numerical problems and the analytical models themselves. While the numerical problems could be addressed by standard computational methods, the lack of physical understanding could only be addressed by experimental means. High magnification photographic methods were utilized to gain a greater understanding of the physical mechanisms involved in the ice accretion process.

\section{Background}

Previously reported efforts have investigated the ice accretion process via close-up photographic methods in the NASA Lewis Research Center Icing Research Tunnel (IRT) (Refs. 8 to 10). Through the use of highly magnified $35 \mathrm{~mm}$ still photography, movies, and video, these studies have described the movement of water on the surface, the growth of ice, and the development of roughness on the ice surface. Some key issues to the analytical modeling of aircraft ice accretion have been addressed by these efforts. These issues include the movement of water on the airfoil surface as drops instead of a thin film, the development of these drops into surface roughness elements, the relationship between roughness formation and boundary layer transition, two different mechanisms for "horn" growth, and the specific nature of ice "feather" growth.

Until the introduction of the close-up video techniques, very little valuable data had been successfully gathered in flight to validate the IRT data. The use of videography allowed the real-time monitoring and adjustments to the camera system. This ability proved to be essential with the high vibration and varying light levels encountered in the flight environment along with the demands of maintaining the focus of the growing ice accretion. Although improvements to the camera system are recommended (see below), the video footage gathered in flight during the winter of early 1993 substantiates a great deal of the earlier IRT data. 


\section{$\underline{\text { Research Aircraft and Data System }}$}

NASA's Icing Research Aircraft is a modified DeHavilland DHC-6 Twin Otter (Fig. 1). Modifications include additional ice protection equipment, an experiment carrier for the overhead hatch, four research racks, and various instruments for measuring the meteorological and flight conditions.

The Twin Otter has been retrofitted with pneumatic boots on the vertical stabilizer, wing struts, and landing gear struts to provide a safe platform for icing flight tests.

The experiment carrier is an elevator system which allows models to be raised and lowered from the cabin through the overhead hatch (Fig. 2). Models are bolted vertically to the experiment carrier platform. The experiment carrier allows models to be stowed in the cabin for take-off and landing, allows models to be introduced to the icing cloud, and provides researchers access to the model and the resulting ice accretion in flight.

There are four research racks in the Twin Otter's cabin area. Three racks contain instrumentation and data systems for recording the icing meteorological and flight data. The fourth rack is reserved for the specific flight experiment.

Primary icing flight data consisted of liquid water content (LWC), droplet size (MVD), outside air temperature (OAT), airspeed, altitude, angle of attack, and angle of sideslip (Ref. 11). The LWC was measured with a JohnsonWilliams probe which was located on the left side of the fuselage near the forward baggage compartment. Droplet size was determined by two Particle Measuring System (PMS) probes. The Forward Scattering Spectrometry Probe (FSSP) measured droplet sizes from 3 to $50 \mu \mathrm{m}$. The Optical Array Probe (OAP) measured droplet sizes from 50 to $300 \mu \mathrm{m}$. Both PMS probes were mounted from hard-points under the left wing, outboard of the engine. The OAT was measured with a Rosemount OAT probe mounted on the right side of the fuselage near the forward baggage compartment. Airspeed and altitude were determined from the impact and static pressures sensed by a Rosemount 858 probe extended from the fuselage on a $9 \mathrm{ft}$ noseboom. Angles of attack and sideslip were also sensed by the Rosemount 858 probe. Transducer signals were amplified and filtered by a Precision Filters System 6000 unit, then digitized and recorded by a Science Engineering Associates data acquisition system. A total of 12 channels of data were digitized at an acquisition rate of $100 \mathrm{samples} / \mathrm{sec}$ and a 16 bit resolution. Data were recorded to 2.2 gigabyte tape cartridges. The data was converted to engineering units and placed in spreadsheet format with a PC-compatible desktop computer.

\section{Description of Camera System}

As discussed above, earlier ice accretion observations were accomplished through the use of motion picture cameras. One of the problems encountered was that the camera was aligned to the airfoil with an extremely oblique viewing angle in order to prevent aerodynamic interference with the airfoil. The major disadvantage to this configuration is that it results in little more than a thick line of the available image area appearing in sharp focus. Additionally, it is not possible to monitor the focus with a film motion picture camera, so as ice accretes, the band of sharp focus eventually moves beyond the image frame.

The solution to these problems was achieved through the modification of the earlier test rig. A video camera was selected in preference to motion pictures because of the ability to monitor the image focus, the comparable light sensitivity to $\mathrm{B} \& \mathrm{~W}$ motion picture film, the availability of high speed gating to prevent motion blur, and the small size of the camera and related equipment. The final obstacle to overcome was the problem of the narrow area of focus. The solution to this was the design and construction of a unique device to take advantage of a phenomenon of optics known as the Scheimpflug rule. The rule states that when the image, lens, and subject planes all intersect at a common point, then the entire scene will be in focus. In a normal photograph, the three planes are parallel and can be said to intersect at infinity. However, due to the constraints of this test, the subject plane is set at a large angle relative to the lens plane. To accommodate this, a hinged lens adapter allowed the adjustment of the image plane relative to the lens plane. Due to varying focus, it was not practical to keep the three planes in exact convergence, however, this was not necessary because simply getting the planes close was acceptable, and resulted in significantly improved images. 
The result of this setup (Fig. 3) was that quality video data was obtained during this experiment. The improvement over images obtained in the past was significant, and the inflight monitoring of recorded image quality allowed real-time camera adjustment or flight plan modification.

Although this new system has improved over methods used in the past, there are some obstacles that have yet to be overcome. Included among these are the problem of vibration. Shaking is visible in the video due the vibration of the airfoil relative to the camera assembly, and possibly vibration within the camera assembly. The only practical solutions are to strengthen and stiffen the structure, or possibly utilize a digitally stabilized image processing system. Additionally, the variability of the natural lighting in the tops of icing clouds caused both under and over exposures of the video images. A fixed artificial light source placed to emphasize the contrast of the ice would solve this problem. Care must be used to ensure that the light source does not disturb the airflow about the airfoil, that the heat from the light does not influence the ice accretion, and that the power and weight constraints of the aircraft and experiment carrier are not violated.

\section{$\underline{\text { Test Article }}$}

The model used for this test was a $8.9 \mathrm{~cm}$ (3.5 in.) diameter aluminum-skinned faired cylinder (Fig. 4). This was the same model that was utilized in the prior IRT tests. The model was attached to the Twin Otter's experiment carrier which was discussed above.

In most cases, the model was extended into the freestream environment after the icing cloud conditions were observed to be stable. For these runs the model surface temperature was above freezing, so the initial (approximately $10 \mathrm{sec}$ ) runback and ice growth were not typical. For a few runs, the model was extended before entering the icing cloud to allow the model to reach the ambient temperature. This method was possible only when there were distinct horizontal limits to the icing clouds. To alleviate this problem, it is recommended that any future work include the capability to keep the model cooled even when retracted into the aircraft cabin.

After retracting the model into the aircraft cabin, the resultant ice accretion was photographed with a hand-held $35 \mathrm{~mm}$ camera and traced by hand to cardboard templates. Since all accretions were small, this information is not presented in this report. After documentation was completed, the model was de-iced and extended into the freestream for another icing run. All carrier extension and retraction times were recorded to allow the correlation of icing cloud environment data to the video tape footage during post-flight analysis.

\section{$\underline{\text { Observations }}$}

\section{Measurement Technique}

The video tape was viewed on a 20 in. color video monitor and the 5 in. color monitor used in flight connected to the S-VHS recorder used in flight. Measurements of roughness and feather size were made with the 20 in. monitor by first taping a viewgraph transparency to the screen and then tracing and measuring the video image. A reference scale on the model, visible in the video, was also traced and measured. The scale measurements allowed the calculation of a conversion from video screen dimensions back to the model dimensions. The screen tracing measurements were then converted to model dimensions. By relating to the time of the measurements, growth rates were calculated. The smaller monitor was valuable for observing general trends in the video image. This configuration worked quite well and is recommended for any future work.

Since the extension and retraction times were recorded, by measuring the run-time of the video tape the image was correlated with the icing cloud environment data. As discussed above, the cloud data was placed into spreadsheet format. A PC-based spreadsheet program was used to manipulate the data to obtain the LWC, MVD, OAT, and velocity values for each period of interest.

\section{Feather Growth Rate Comparison to IRT Data}

A total of 104 growth rate measurements were made for 21 different feathers. To make the data more manageable, growth rate and environmental data were then averaged for each feather. Figure 5 shows the growth rates of each feather versus their water mass flux, which is defined as the freestream velocity times the LWC (Ref. 10), and the linear fit of this data. Figure 6 shows the flight data and its fit, and the IRT data (Ref. 10) and its linear fit. Considering the number of 
points used to calculate both fits, the agreement seems very good. This indicates that the feather growth rate versus water mass flux slope measured in the IRT is appropriate for flight and for lower flux values. It should be noted that this slope may only be appropriate for the $8.9 \mathrm{~cm}$ (3.5 in.) diameter faired cylinder. As will be seen later, the influence of the water mass flux upon the feather growth rate is likely tied to the surface geometry.

\section{Influence of MVD on Feather Growth Rate}

During the development of data describing the influence of water mass flux upon the feather growth rates, an interesting trend became apparent. When the data was separated by droplet size, the slopes were altered. Figures 7 to 10 display linear fits for each subgroup of points. When these new fits are graphed on the same plot, as in Fig. 11, the dependency upon droplet size becomes obvious. An expression was developed using the curve fitting routine within a PC based graphics package (Ref. 12). Of the many forms attempted, the most appropriate was a linear dependence on both the water mass flux and the droplet size with a constant offset. The expression developed is

Growth Rate $=0.0001612 *$ Flux $+0.0001422 *$ MVD-0.002581,

where the offset is required due to the introduction of the droplet size correction. Figure 12 shows a feather growth rate calculated with the expression above along with the original data. One can see that the expression accounts for the same level of apparent scatter as the original data.

\section{Physical Model for Feather Accretion}

The cause of the droplet size dependency is not completely clear. Since feathers accrete past the region of direct droplet impingement on the clean airfoil, their growth rate is not perceived to be related to the collection efficiency of the model surface. However, their growth rate is dependent on the droplet trajectories that are just off the surface of the model This will be made more clear by examining Fig. 13. This figure shows three droplet trajectories. Trajectory "A" represents a droplet hitting the surface perpendicularly. Trajectory "B" represents a droplet hitting the surface nearly tangentially. The water droplets that fall between trajectories "A" and "B" make up the mass of water that is normally utilized for ice accretion calculations on the clean wing, and trajectory "B" represents the limit of impingement where the surface local collection efficiency goes to zero. Trajectory " $\mathrm{C}$ " represents a droplet that will hit the edge of a roughness element protruding from the surface aft of the limit of impingement defined above. It is the water droplets between trajectories "B" and " $\mathrm{C}$ " that are of interest here. These are the droplets that will hit the roughness element and begin to grow into an ice feather. Therefore, it is the concentration of droplets in this off-body layer that controls the rate of feather growth. The feather growth rate expression developed above must already have this factor included, and this is what introduces the dependency upon the droplet size. For the concentration of water in this off-body layer is dependent not only on LWC and velocity, but also the droplet size. And as mentioned above, this also leads to the dependency upon the surface geometry. Just as the surface collection efficiency is dependent upon the drop size and surface geometry, the concentration of water in the off-body layer will also be dependent upon drop size and surface geometry. Therefore, one cannot expect to be able to apply the feather growth rate expression developed above to any geometry other than the $8.9 \mathrm{~cm}(3.5 \mathrm{in}$.) diameter faired cylinder.

\section{Different Feather Shapes Observed}

During the examination of the video footage, it became apparent that a large number of the feathers observed had a more acute growth angle than others. This trend was not observed in the IRT. Figure 14 shows a "normal" ice feather that was photographed in the IRT. This is considered normal because the vast majority of feathers observed have this general shape. Figure 15 shows an example of the more acute feather growth angles that were occasionally observed in flight (note that the flow direction in Fig. 15 is from the top left to the bottom right of the field of view). No clear trend was discernable in the flight data to explain the feather angle trends. Personne, in his investigations (Ref. 13), also observed variations in the growth angles of feathers, but could also not identify any clear source to this variability. Since the environment for many of these flights consisted of fairly localized and variable icing conditions, and since the flight conditions are generally a lower LWC than those examined in the IRT, then it is speculated that this sharper angling is related to the spottier,lower LWC experienced. However, if the angle of the feather growth is found to be an important parameter for the ice prediction codes, then this variability will have to be further investigated. 
Feather Shedding and Ice Sublimation

Another interesting observation from flight is that the shedding of feathers and the sublimation of ice can contribute to a change in the ice shape through the modification of the aft limit of remaining ice. These trends were not seen to this extent in the IRT and this is likely for several reasons. The reason for enhanced shedding in flight is probably due to the vibration levels experienced in flight coupled with the narrower, more delicate feathers sometimes seen in flight (as discussed above). The reason for enhanced ice sublimation is due to the spotty nature of the flight liquid water. As an example of these processes, Figs. 16 and 17 show before and after images of the same region of the model that experienced localized feather shedding and ice sublimation during a period of overall ice growth. Figure 18 displays the sharp aft limit of remaining ice which results after such ice shed and sublimation. Since existing ice accretion codes do not address the concept of ice mass loss of existing ice, future codes which will include the modeling of feather growth must address these two mechanisms.

\section{Lack of Influence of Snow on Ice Accretion}

The last point to be reported is the apparent lack of influence the snow encountered in flight had on the observed ice accretions. It is fairly normal to encounter snow during research icing flights. Very often the cells of clouds with liquid water are surrounded by snow generated as the cloud glaciates. In these cases, flying from cell to cell one observes a fairly stable LWC and drop size, then a transition to either all snow or part snow/part liquid water, and then another transition to stable LWC and drop size. This occurred on several of the flights documented here. Figure 19 shows an ice accretion from one of these flights. The image was taken immediately after several snow flakes hit the surface of the ice. As the aircraft reentered the liquid water droplet environment, the snow flakes were very quickly absorbed by the ice accretion. They had no effect on the shape of the ice accretion or even the level of roughness on the surface. The snow flakes contribute so little mass, that their presence is negligible. While this may not be true for all possible cases, this appears to hold true for the kind of conditions normally encountered with the NASA Lewis Research Center Twin Otter Icing Research Aircraft. This then substantiates the current method of neglecting all frozen moisture encountered and only measuring and recording the liquid water (ie., LWC and drop size information).

\section{Conclusions}

High magnification video observations of the ice accretion process on a $8.9 \mathrm{~cm}$ (3.5 in.) diameter aluminum-skinned faired cylinder have been conducted in flight on the NASA Lewis Research Center Twin Otter Icing Research Aircraft. Key points that these observations have brought to light are: (1) The measured flight feather growth rate is consistent with IRT values, (2) The feather growth rate appears to be influenced by droplet size, (3) The feathers were straighter in the lower, spottier LWC of flight in comparison to those observed in the IRT, (4) Feather shedding and ice sublimation may be significant to the final ice shape, (5) The snow encountered on these flight appeared to have little influence on ice growth.

\section{$\underline{\text { References }}$}

1. Ackley, S.F. and Templeton, M.K.,"Computer Modeling of Atmospheric Ice Accretion," U.S. Army Cold Regions Research and Engineering Laboratory, CRREL Report 79-4, ADA 068582, 1979.

2. Lozowski, E.P., Stalabrass, J.R., and Hearty, P.F., "The Icing of an Unheated Non-Rotating Cylinder in Liquid Water Droplet-Ice Crystal Clouds," NRC of Canada Report LTR-LT-96, 1979.

3. Hankey, W.L. and Kirchner, R., "Ice Accretion on Wing Leading Edges," AFFDL-TM-85-FXM, 1979.

4. Cansdale, J.T. and Gent, R.W., "Ice Accretion on Aerofoils in Two-Dimensional Compressible Flow - A Theoretical Model," Royal Aircraft Establishment Technical Report 82128, 1983.

5. Guffond, D.P., "Icing and De-Icing Test on a 1/4 Scale Rotor in the ONERA S1MA Wind Tunnel," AIAA-86-0480, Jan. 1986.

6. Ruff, G.A., and Berkowitz, B.M., "Users Manual for the NASA Lewis Ice Accretion Prediction Code (LEWICE)," NASA CR-185129, May 1990.

7. Paraschivoiu, I., Tran, P., Brahimi, M.T., "Prediction of the Ice Accretion with Viscous Effects on Aircraft Wings," AIAA-93-0027, Jan. 1993.

8. Olsen, W., and Walker, E., "Experimental Evidence for Modifying the Current Physical Model for Ice Accretion on Aircraft Surfaces," NASA TM-87184, 1986.

9. Hansman, R.J., "Analysis of Surface Roughness Generation in Aircraft Ice Accretion," AIAA-92-0298, Jan. 1992.

10. Hansman, R.J., Breuer, K.S., Hazan, D., Reehorst, A.L., and Vargas, M., "Close-up Analysis of Aircraft Ice Accretion," NASA TM-105952, AIAA-93-0029, Jan. 1993. 
11. Ide, R.F., and Richter, G.P., "Comparison of Icing Cloud Instruments for 1982-1983 Icing Season Flight Program," NASA TM-83569, USAAVSCOM-TR-84-C-1, Jan. 1984

12. SigmaPlot Scientific Graph System, Jandel Scientific, 1992.

13. Personne, P., "Effect of Roughness on the Growth of Ice at Low Speeds: Experimental Results and Simulation," NASA TT-21405, Sept. 1993, translation of "Effet de Rugosite sur la Croissance Du Givre a Faible Vitess: Resultats Experimntaux et Modelisation", Doctoral Thesis, Universite Blaise Pascal, June 1988.

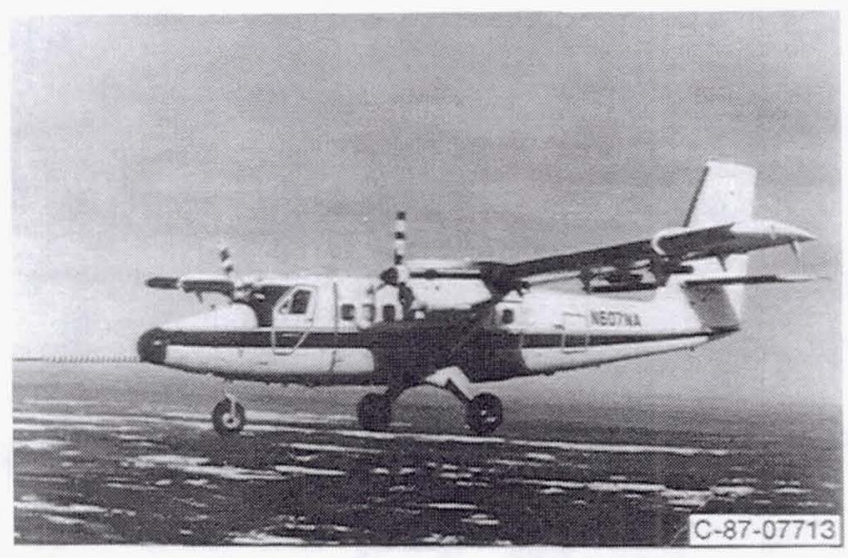

Figure 1.-NASA Lewis Research Center Twin Otter Icing Research Aircraft.

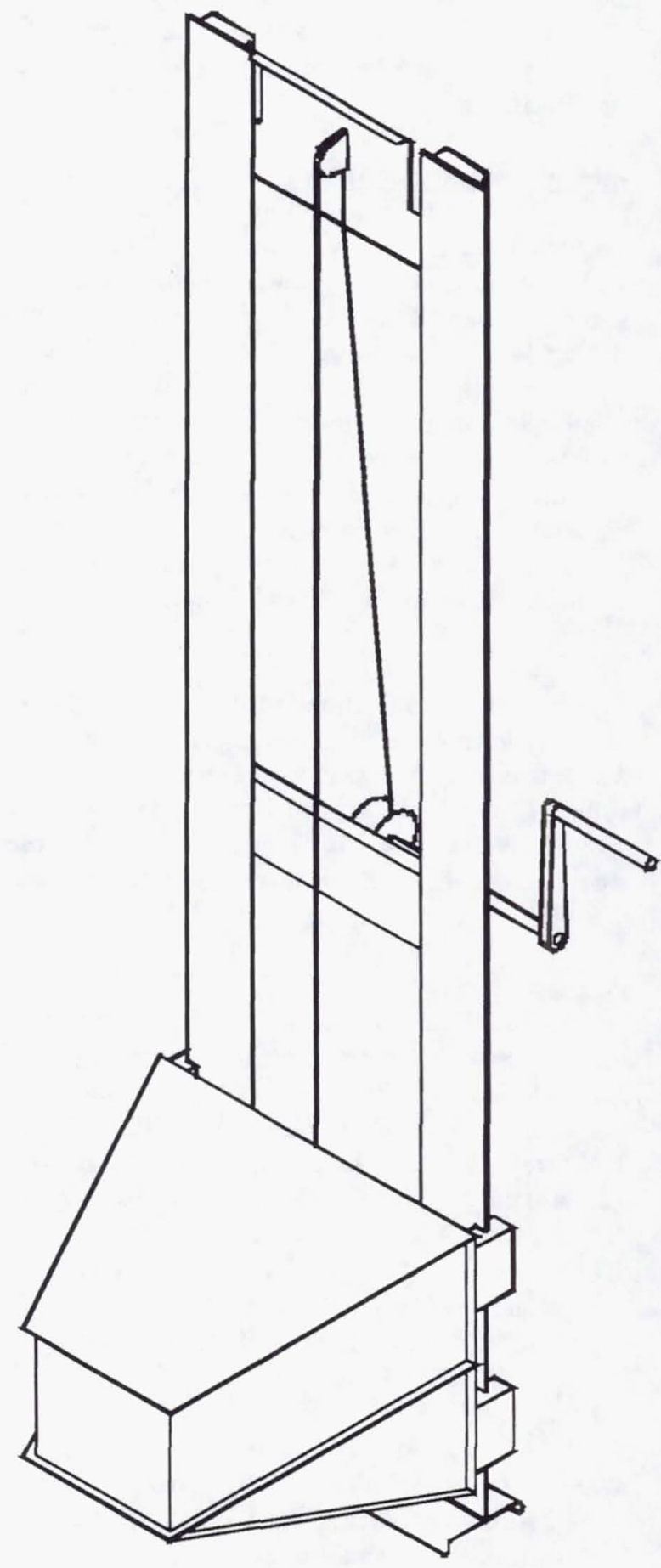

Figure 2.-Twin Otter experiment carrier. 


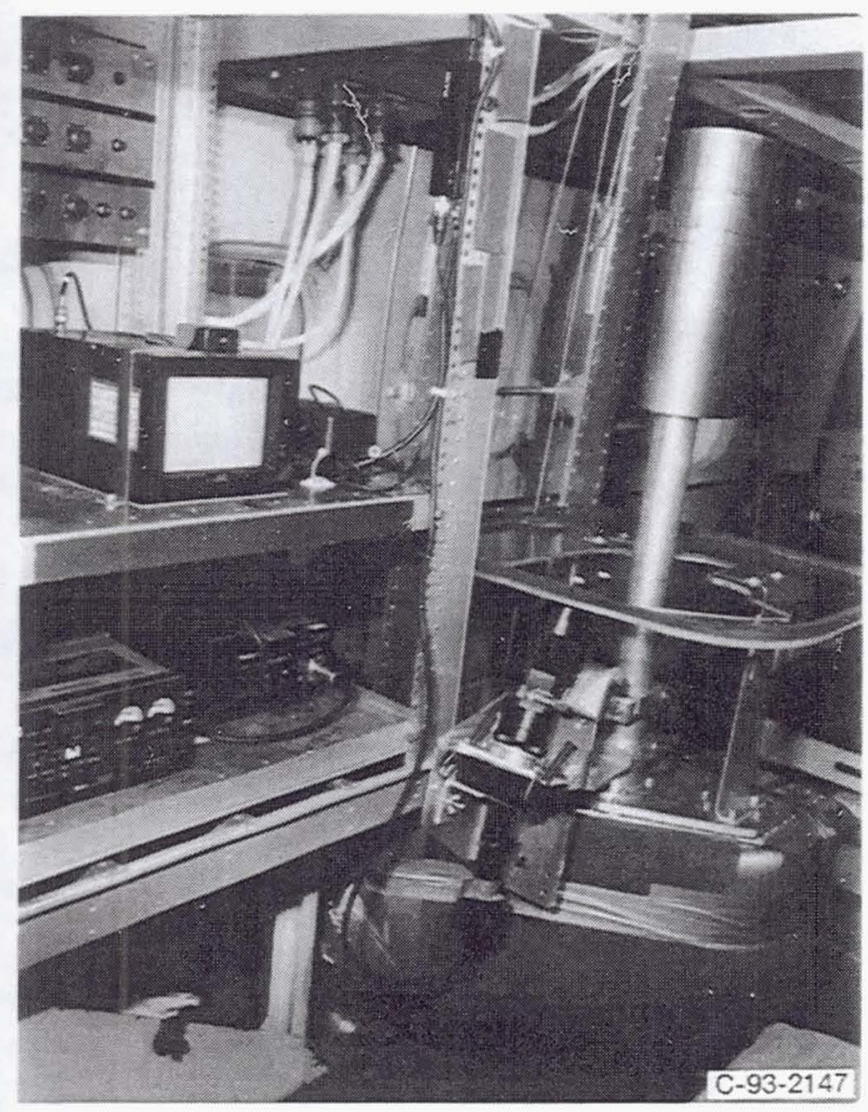

Figure 3.-Close-up video camera installation on Twin Otter Aircraft.

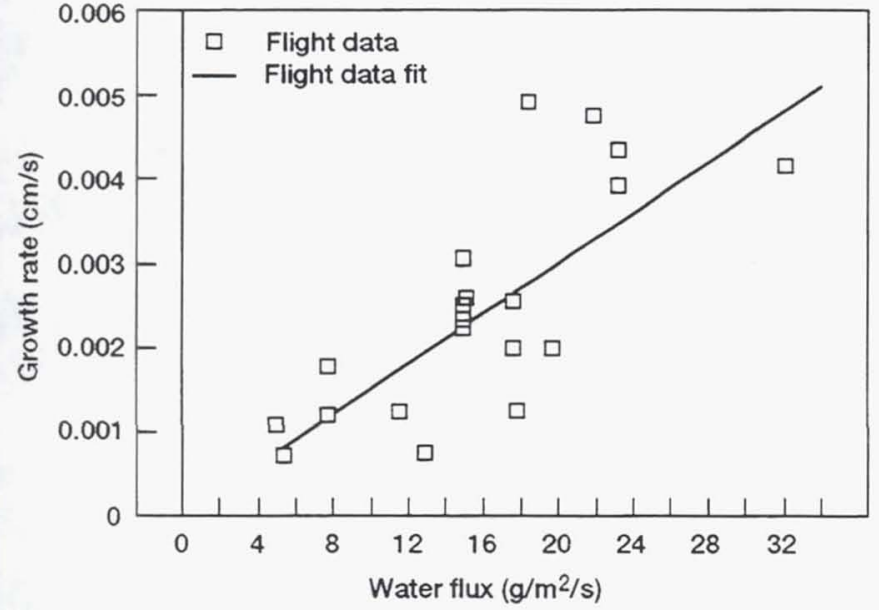

Figure 5.-Flight ice feather growth rate versus water flux for MVD $=0-30 \mu \mathrm{m}$

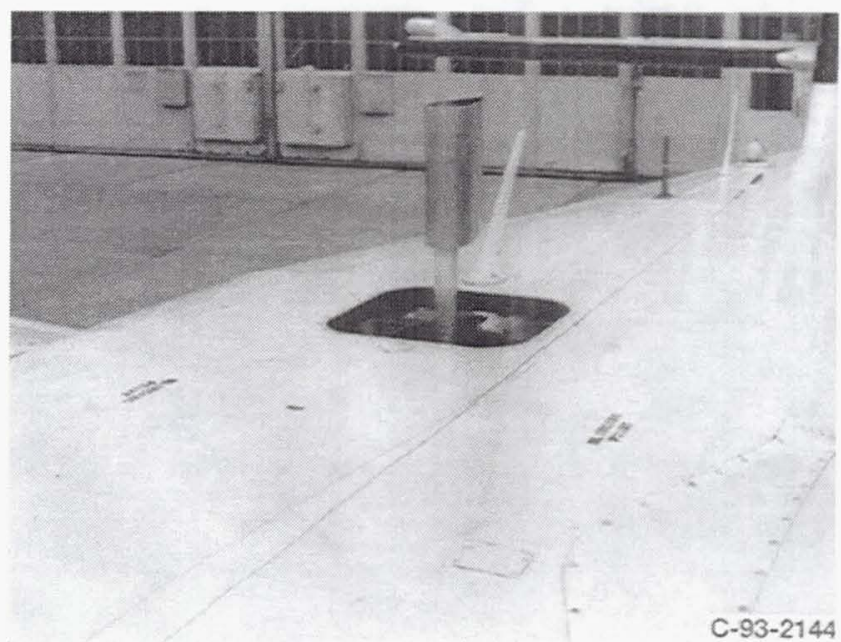

Figure $4 .-8.9 \mathrm{~cm}$ (3.5 in.) diam. aluminum-skinned faired cylinder model.

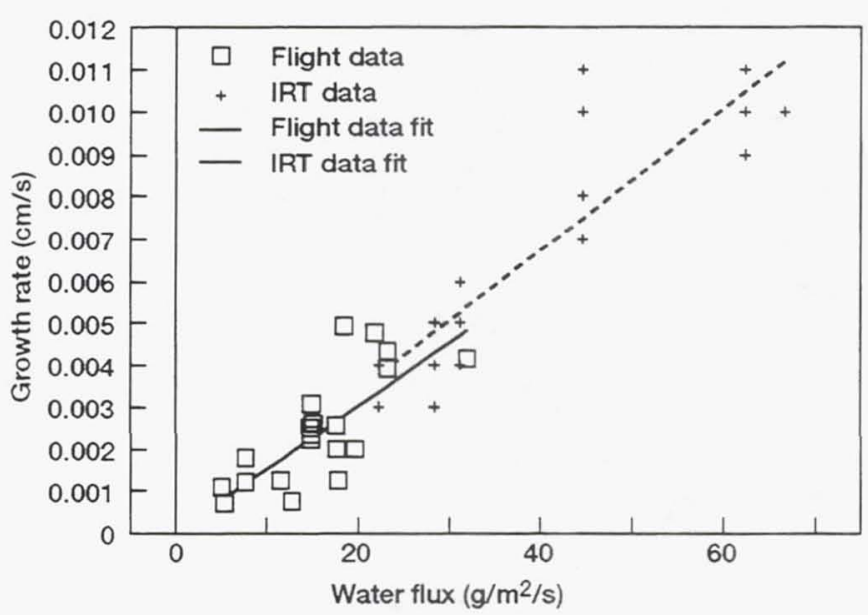

Figure 6.-Flight and IRT feather growth rate versus water flux. 


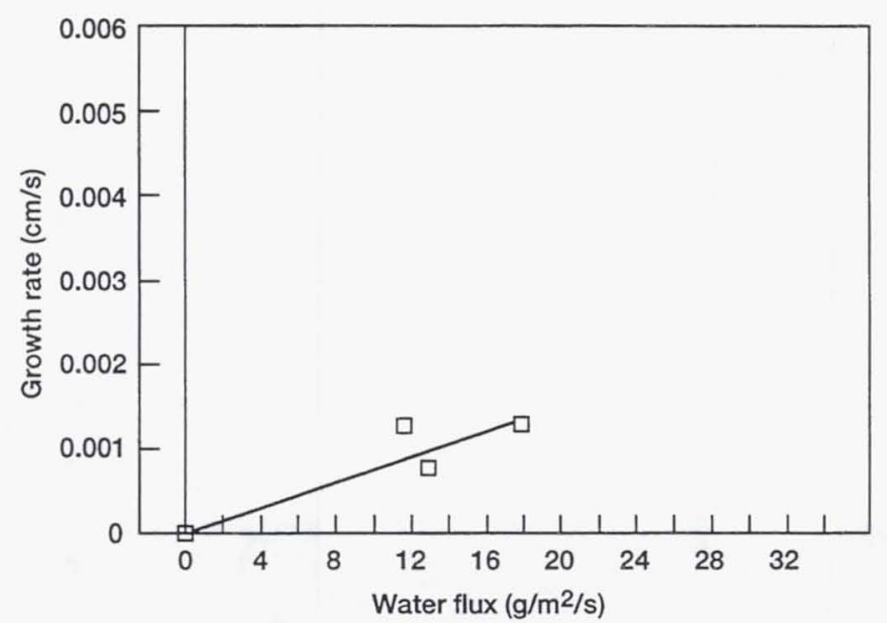

Figure 7.-Feather growth rate versus water flux for $M V D=10-12 \mu \mathrm{m}$.

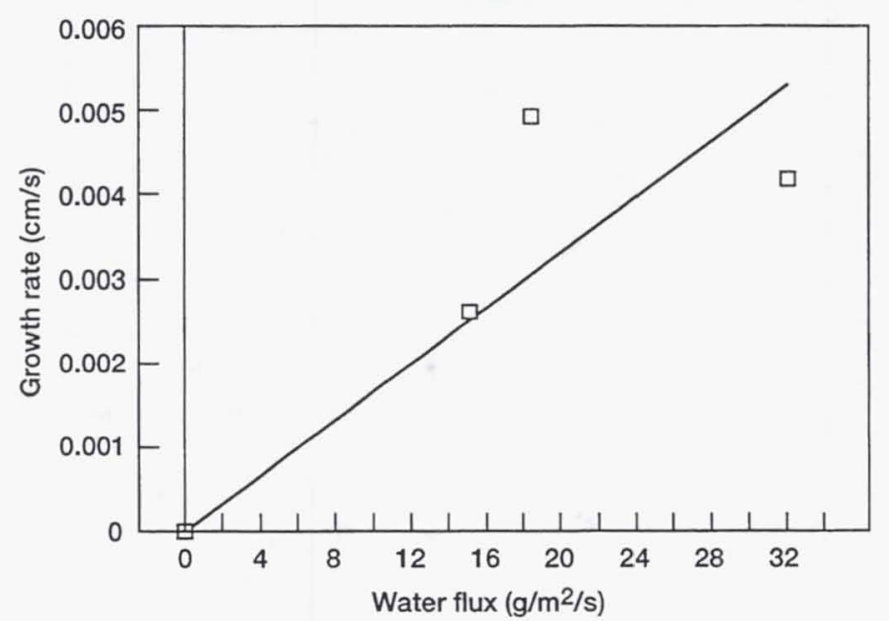

Figure 9.-Feather growth rate versus water flux for MVD $=17-20 \mu \mathrm{m}$.

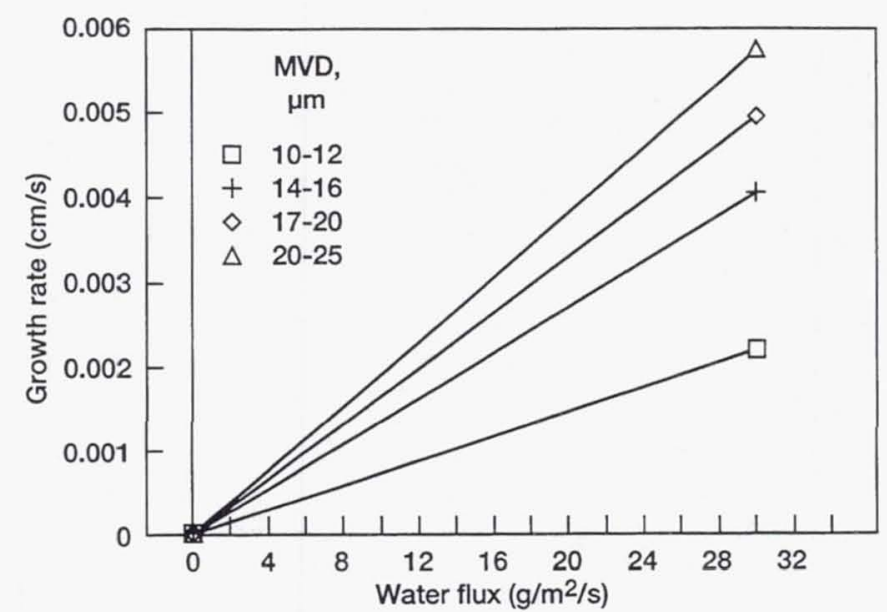

Figure 11.-Feather growth rate curve fits for all measurements.

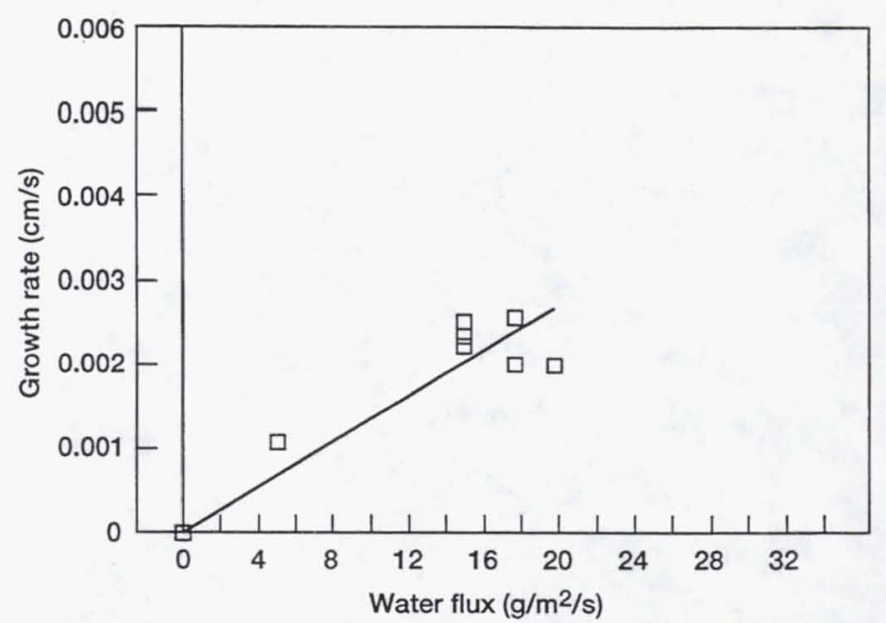

Figure 8.-Feather growth rate versus water flux for MVD $=14-16 \mu \mathrm{m}$.

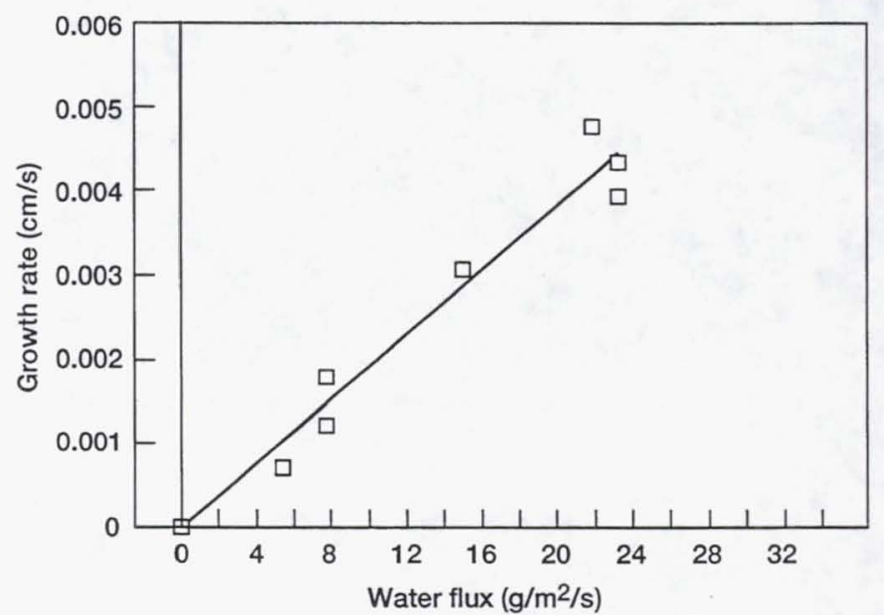

Figure 10.-Feather growth rate versus water flux for MVD $=20-25 \mu \mathrm{m}$.

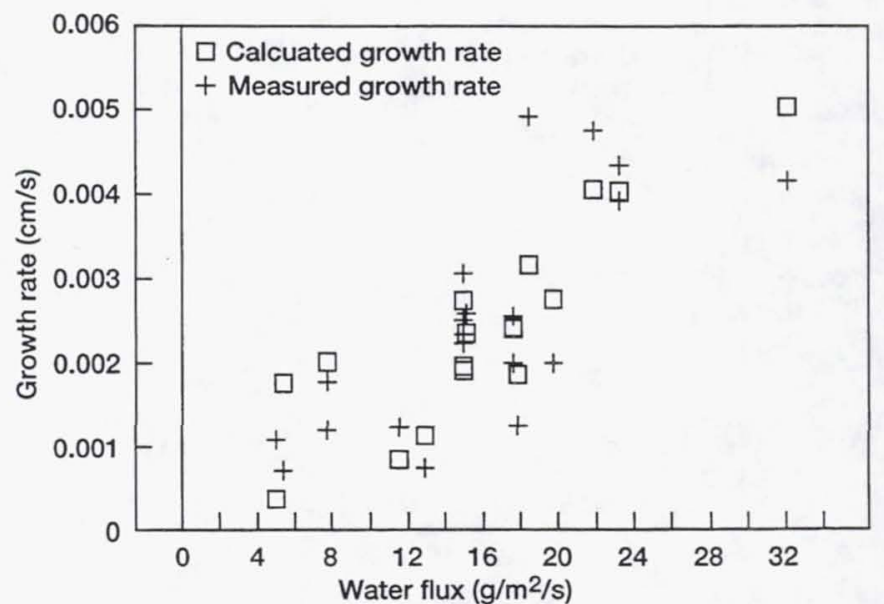

Figure 12.-Fitted and measured feather growth rates versus water flux. 


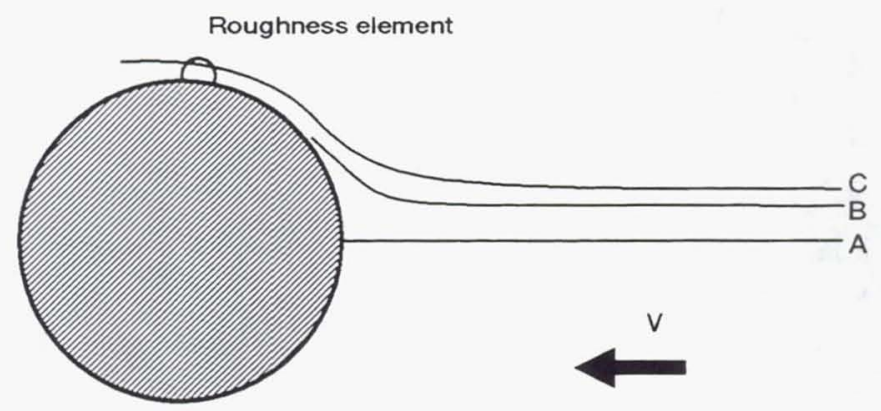

Figure 13.-Representation of droplet trajectories controlling feather growth.

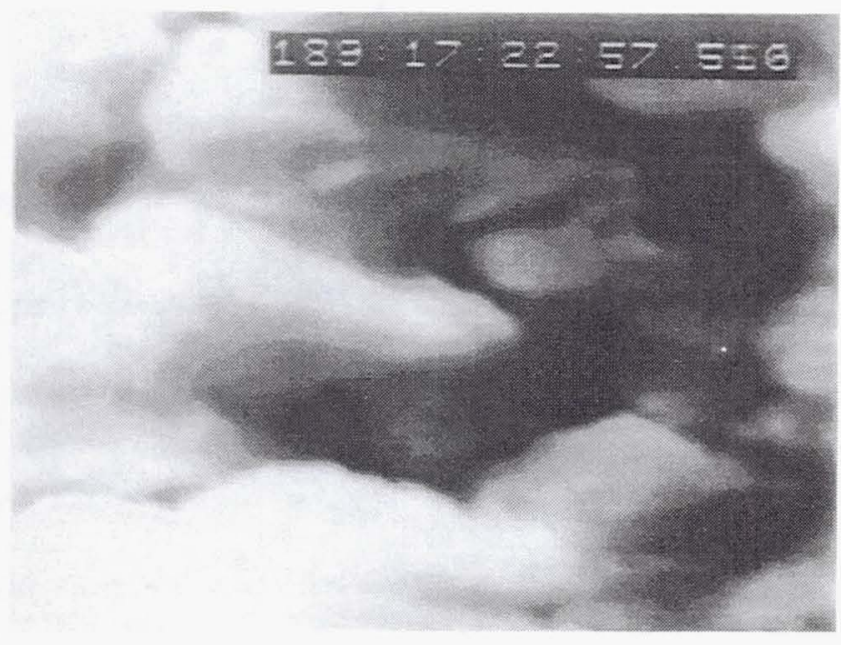

Figure 14.-Feather accretion from IRT showing "normal" growth angle.

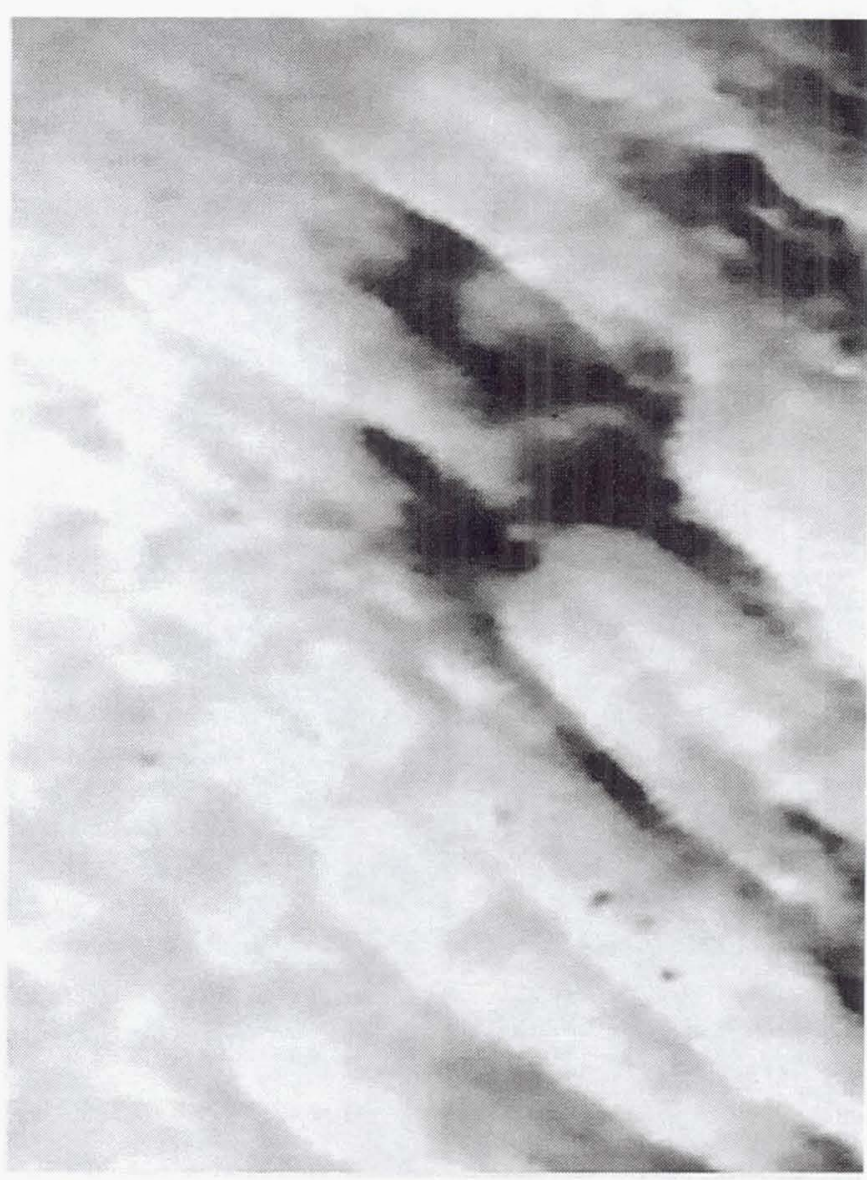

Figure 15.-Inflight feather showing small growth angle. 


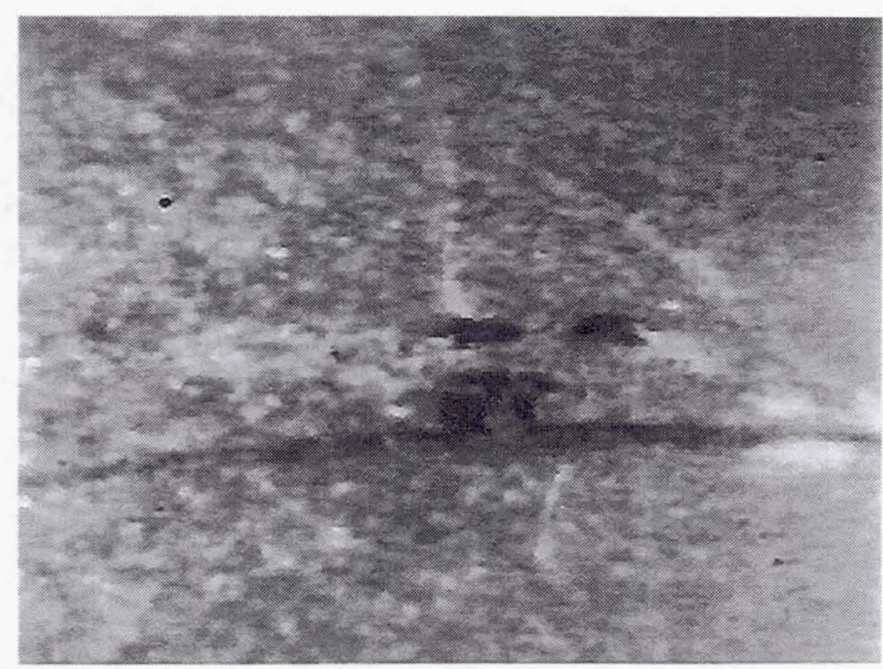

Figure 16.-Feather and ice formation before shed and sublimation.

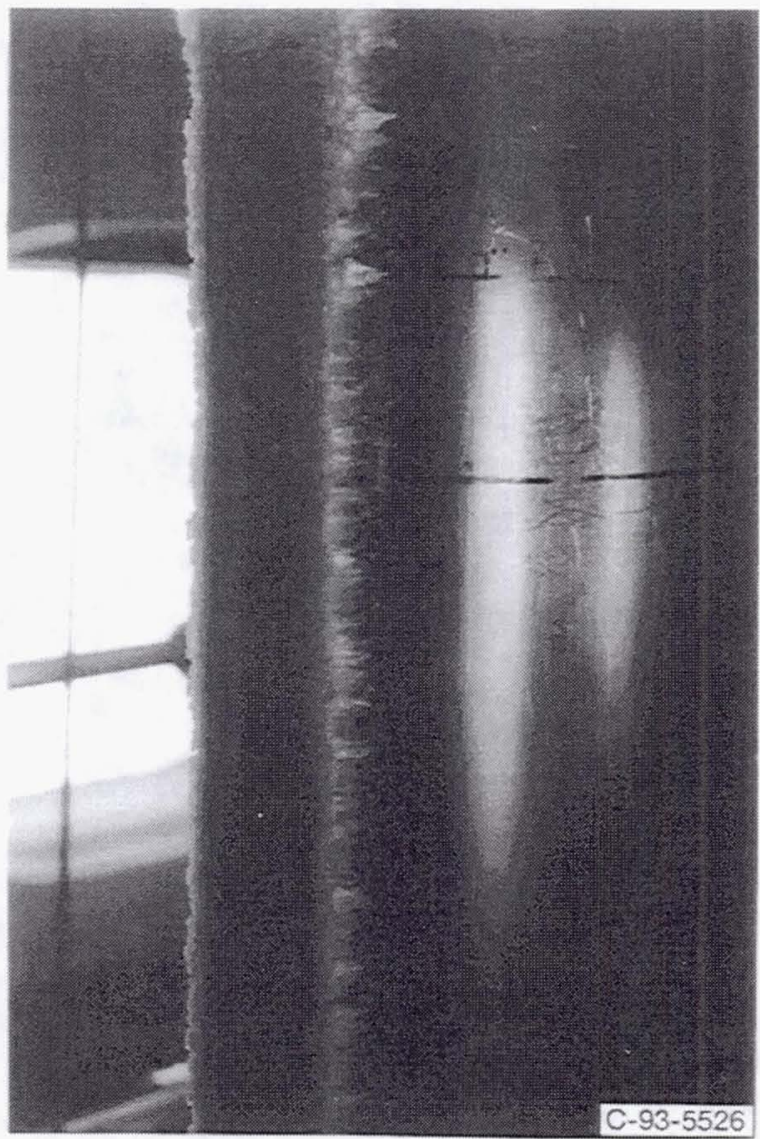

Figure 18.-Photograph of resultant ice shape where feather shedding and subilimation occurred.

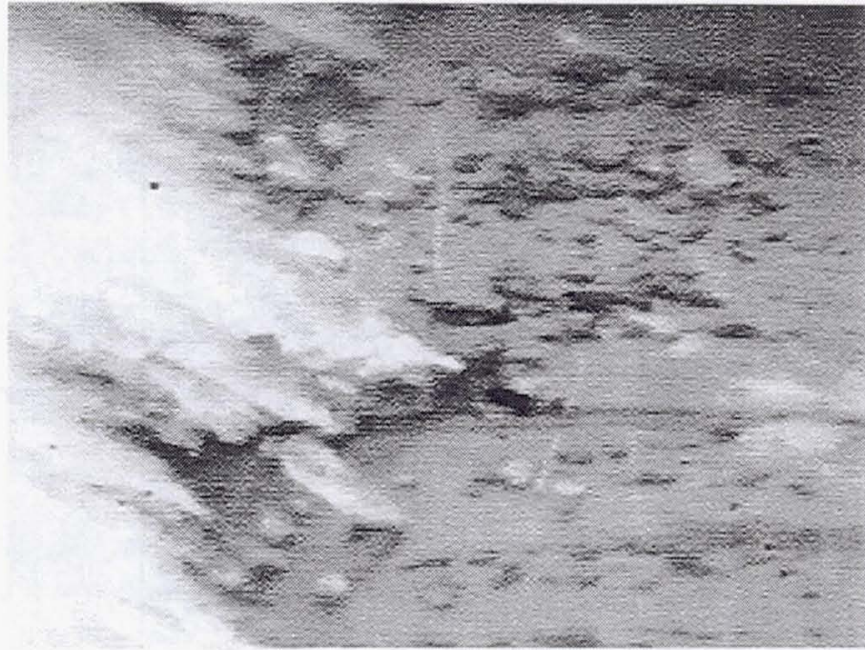

Figure 17.-Feather and ice formation after shed and sublimation.

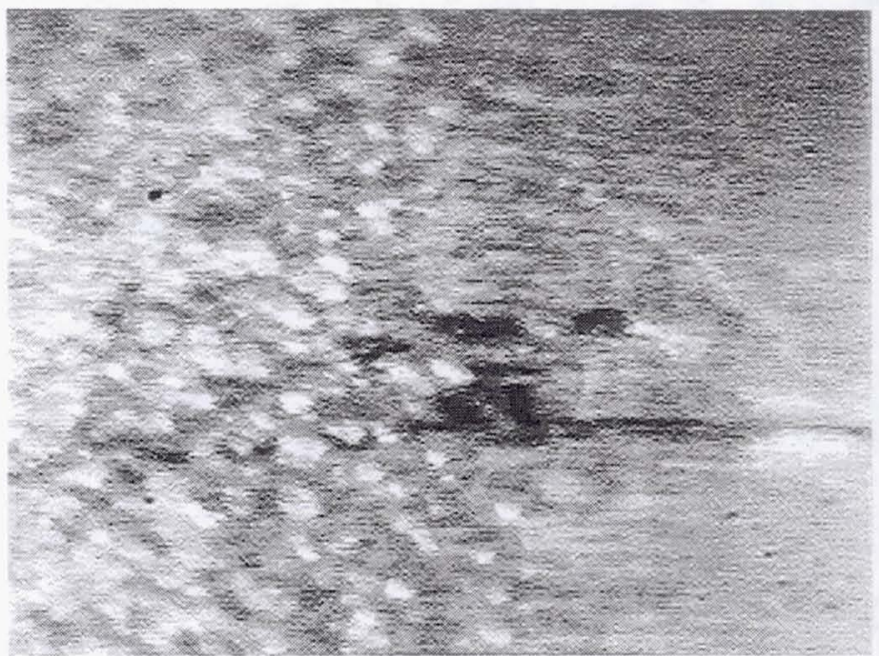

Figure 19.-lce accretion showing lack of influence of snow on overall shape. 
Public reporting burden for this collection of information is estimated to average 1 hour per response, including the time for reviewing instructions, searching existing data sources, gathering and maintaining the data needed, and completing and reviewing the collection of information. Send comments regarding this burden estimate or any other aspect of this collection of information, including suggestions for reducing this burden, to Washington Headquarters Services. Directorate for Intormation Operations and Reports, 1215 Jefferson Davis Highway, Suite 1204, Arlington, VA 22202-4302, and to the Office of Management and Budget. Paperwork Reduction Project (0704-0188), Washington, DC 20503.

\begin{tabular}{|l|l|l|l}
\hline 1. AGENCY USE ONLY (Leave blank) & $\begin{array}{c}\text { 2. REPORT DATE } \\
\text { January } 1994\end{array}$ & $\begin{array}{l}\text { 3. REPORT TYPE AND DATES COVERED } \\
\text { Technical Memorandum }\end{array}$ \\
\hline
\end{tabular}

\section{TITLE AND SUBTITLE}

Close-up Analysis of Inflight Ice Accretion

\section{FUNDING NUMBERS}

6. AUTHOR(S)

Andrew L. Reehorst, Thomas P. Ratvasky and James Sims

7. PERFORMING ORGANIZATION NAME(S) AND ADDRESS(ES)

National Aeronautics and Space Administration

Lewis Research Center

Cleveland, Ohio 44135-3191

WU-505-68-10

9. SPONSORING/MONITORING AGENCY NAME(S) AND ADDRESS(ES)

National Aeronautics and Space Administration

Washington, D.C. 20546-0001

8. PERFORMING ORGANIZATION REPORT NUMBER

E-8318

10. SPONSORING/MONITORING AGENCY REPORT NUMBER

NASA TM-106457

AIAA-94-0804

11. SUPPLEMENTARY NOTES

Prepared for the 32nd Aerospace Sciences Meeting and Exhibil sponsored by the American Institute of Aeronautics and Astronautics, Reno, Nevada, January 10-13, 1994. Andrew L. Reehorst and Thomas P. Ratvasky, NASA Lewis Research Center and James Sims, Cortez III Service Corporation, 3001 Aerospace Parkway, Brook Park, Ohio 44142 (worked funded by NASA Contract NAS3-24816). Responsible person, Andrew L. Reehorst, (216) 433-3938.

12a. DISTRIBUTION/AVAILABILITY STATEMENT

12b. DISTRIBUTION CODE

Unclassified - Unlimited

Subject Category 03

13. ABSTRACT (Maximum 200 words)

The objective of this effort was to validate in flight, data that has been gathered in the NASA Lewis Research Center's Icing Research Tunnel (IRT) over the past several years. All data was acquired in flight on the NASA Lewis Research Center's Twin Otter Icing Research Aircraft. A faired 3.5 in. diameter metal-clad cylinder exposed to the natural icing environment was observed by a close-up video camera. The grazing angle video footage was recorded to S-VHS video tape and after the icing encounter, the resultant ice shape was documented by $35 \mathrm{~mm}$ photography and pencil tracings. The feather growth area was of primary interest; however, all regions of the ice accretion, from the stagnation line to the aft edge of runback were observed and recorded. After analysis of the recorded data several interesting points became evident: (1) The measured flight feather growth rate is consistent with IRT values, (2) The feather growth rate appears to be influenced by droplet size, (3) The feathers were straighter in the lower, spottier LWC of flight in comparison to those observed in the IRT, (4) Feather shedding and ice sublimation may be significant to the final ice shape, (5) The snow encountered on these flights appeared to have little influence on ice growth.

\section{SUBJECT TERMS}

Aircraft icing; Ice accretion

15. NUMBER OF PAGES

12

16. PRICE CODE

$\mathrm{AO3}$
17. SECURITY CLASSIFICATION OF REPORT

Unclassified
18. SECURITY CLASSIFICATION OF THIS PAGE

Unclassified
19. SECURITY CLASSIFICATION OF ABSTRACT Unclassified 


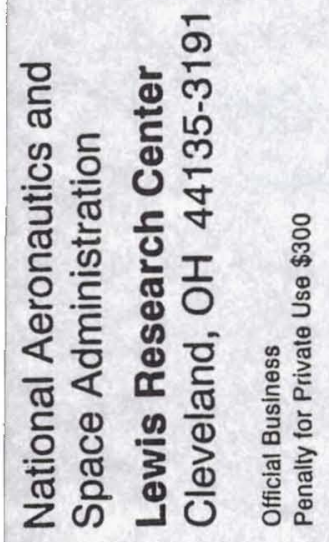

